http://archimer.ifremer.fr/doc/00435/54639/

(C) The Author(s) 2018 Reprints and permissions:

sagepub.co.uk/journalsPermissions.nav

\title{
Numerical and experimental modeling of offshore wind energy capture: Application to reduced scale model testing
}

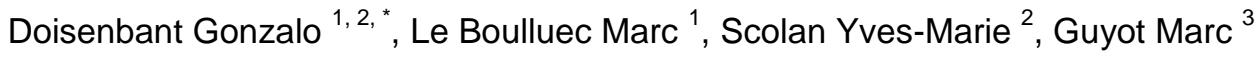

${ }^{1}$ Institut français de recherche pour l'exploitation de la mer (Ifremer), Plouzané, France

2 École nationale supérieure de techniques avancées Bretagne (ENSTA Bretagne), Brest, France

${ }^{3}$ Eolink, Plouzané, France

* Corresponding author : Gonzalo Doisenbant, email address :

Gonzalo.Doisenbant@ensta-bretagne.org

\begin{abstract}
:
Horizontal axis wind turbines installed on board floating supports stand among the principles of offshore wind energy capture. This document describes the experimental device and methodology for analyzing the performance of a reduced scale model of a $12 \mathrm{MW}$ horizontal axis floating wind turbine. The particularity of this turbine is that it is mounted on a floater conceived according to Eolink's concept, where several masts connect the nacelle with the floater. The tests are performed at Ifremer's ocean basin. For that purpose, a wind generator and a model at scale 1:50 are developed. The experimental results are compared with numerical estimations obtained with the blade element momentum method.
\end{abstract}

Keywords : Offshore wind energy, model testing, horizontal axis wind turbine (HAWT), floating bodies, pitch angle, blade element momentum 


\section{Introduction}

Floating wind farms are expected to be the technical and economical solution to extract wind energy in deep water seas (more than $50 \mathrm{~m}$ ).

The coupling behavior between the floating support and the turbine induces control requirements of the turbine operating parameters. In particular the pitch of the blades can be controlled by the overall movement and the time variation of the incident wind and waves. Depending on the type of floater, the control strategy can evolve.

This work aims at performing experimental and numerical modelling of a floating horizontal axis wind turbine (HAWT). Experiments are performed in a tank where waves and wind are generated. The experimental results consist of the performance of the rotor for different pitch angles. Comparisons with numerical estimations are presented.

\section{The experimental model}

The experiences are performed in Ifremer's deep wave ocean basin. It is $50 \mathrm{~m}$ long and $12.5 \mathrm{~m}$ wide, with a depth of $10 \mathrm{~m}$ along $37.5 \mathrm{~m}$ and a depth of $20 \mathrm{~m}$ on the remaining $12.5 \mathrm{~m}$ (Figure 1). Generated waves can be either regular or irregular with a maximal amplitude peak-trough of $0.55 \mathrm{~m}$. The period of the waves is between $0.8 \mathrm{~s}$ and $3 \mathrm{~s}$. 


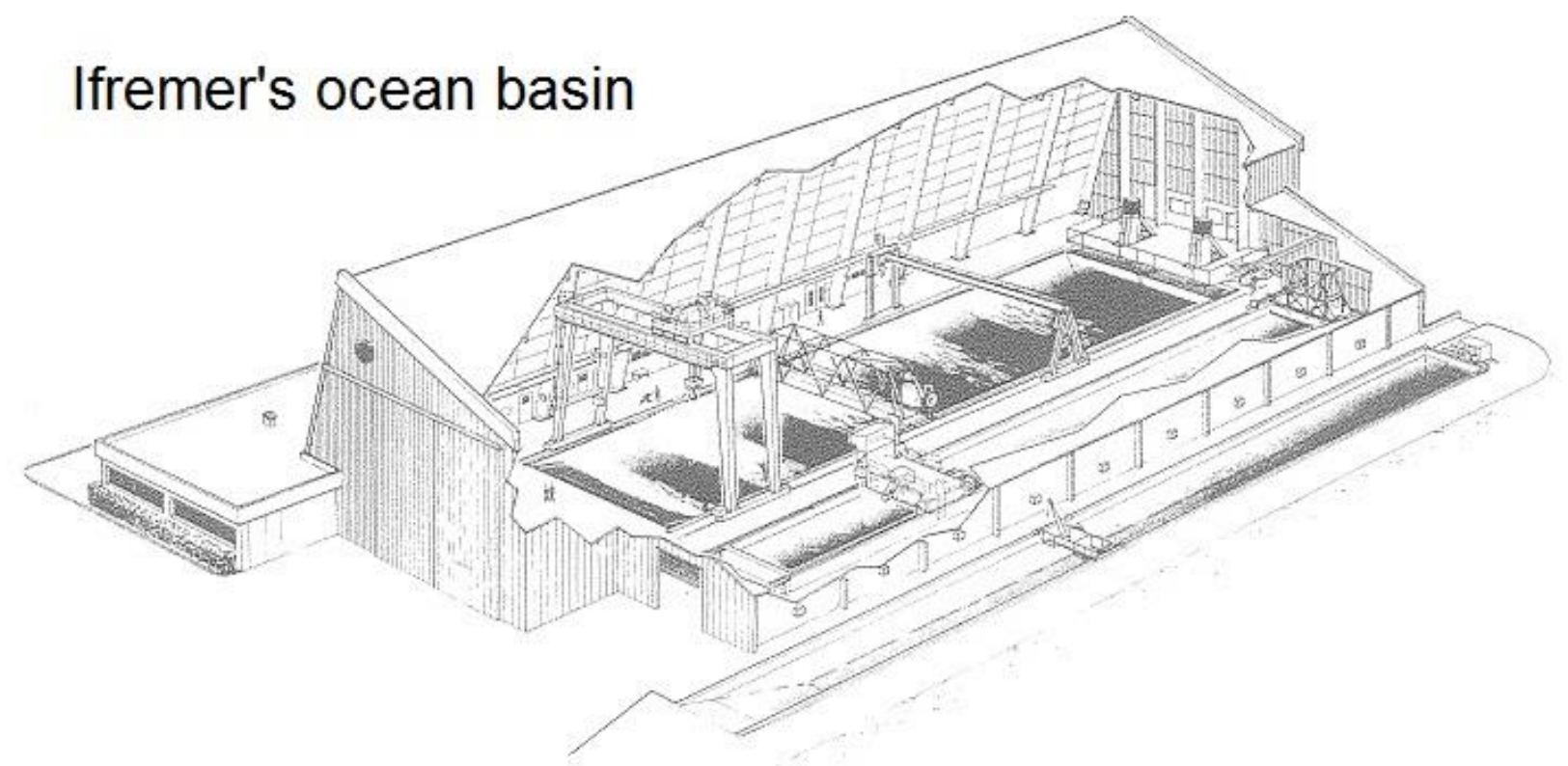

wave generator

length: $50 \mathrm{~m}$ width: $12,5 \mathrm{~m}$

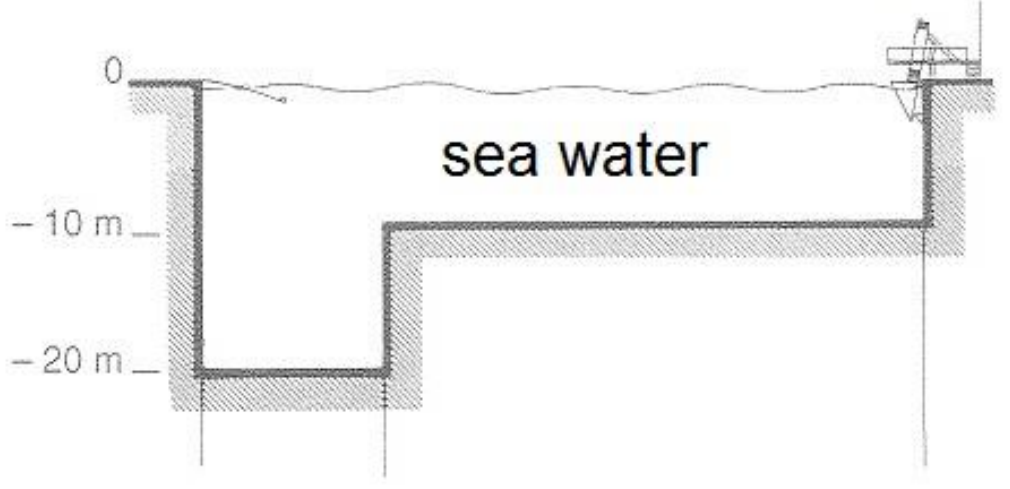

Figure 1: Ifremer's deep wave ocean basin

In order to combine wind and waves, a wind generator is installed above the free surface.

\section{The wind generator}

The wind generator is conceived following a numerical and experimental study carried out by CSTB (Ohana et al., 2014). It consists on twelve $1 \mathrm{~m}$ diameter axial ventilators, arranged in three rows of four fans as shown in Figure 2. The cross section of wind generation is $4.3 \mathrm{~m}$ wide and $3.2 \mathrm{~m}$ high. Each ventilator is associated to an individual asynchronous motor with a maximal power of $9 \mathrm{~kW}$, and each row is controlled independently by a $37 \mathrm{~kW}$ inverter. The produced wind speed may reach 
$9 \mathrm{~m} / \mathrm{s}$. For a better control of the rotational speed of the fans, dissipative resistors have been added, allowing fast stopping of the fans and variable wind generation.

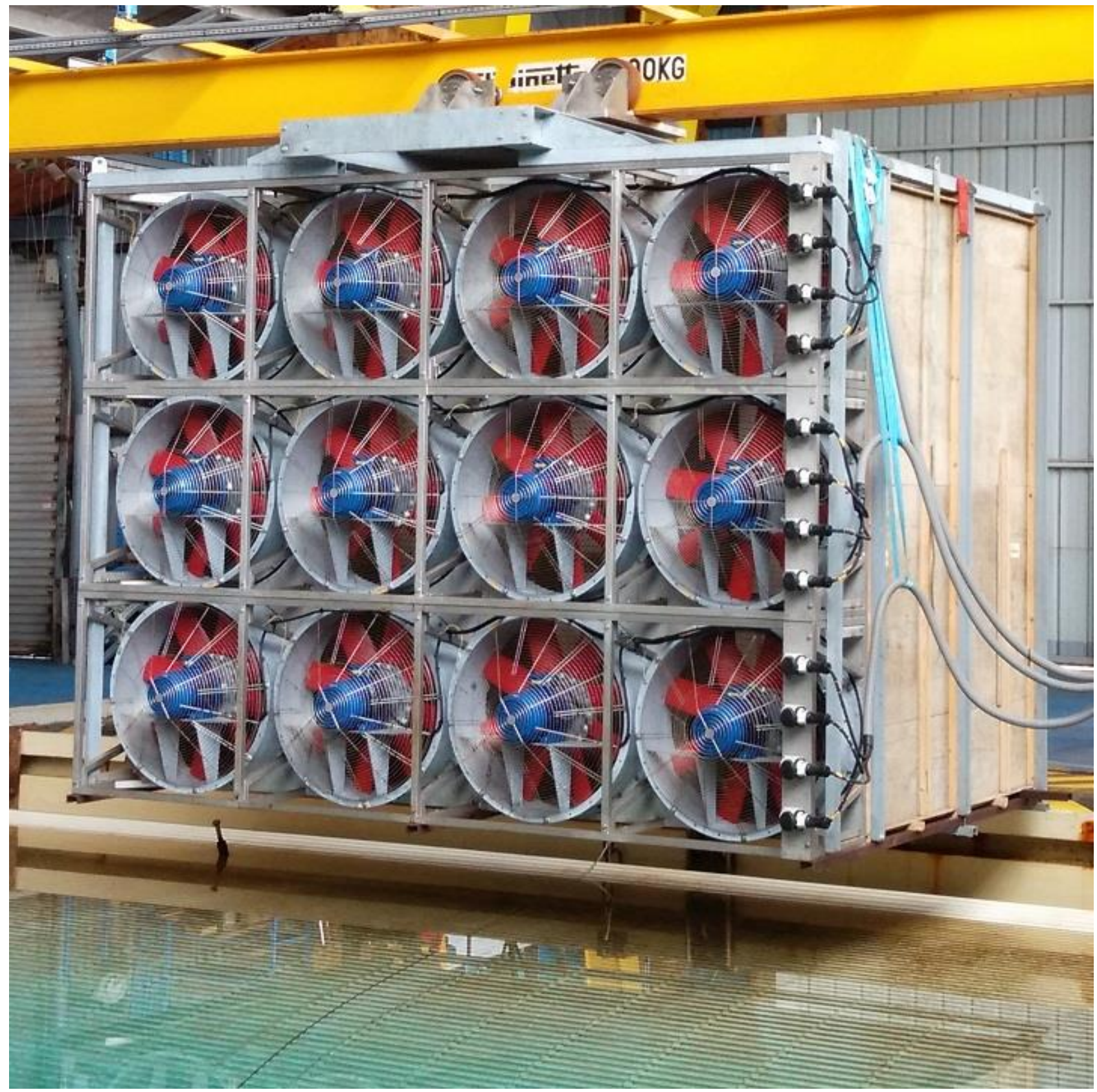

Figure 2: Arrangement of the fans in the wind generator.

The wind speed produced by the ventilators has a strong rotational component; hence special flow straighteners are used to get a homogeneous flow with good directionality and low turbulence (Figure 3). The straightener used by Ifremer is designed according to Mehta and Bradshaw (1979). 


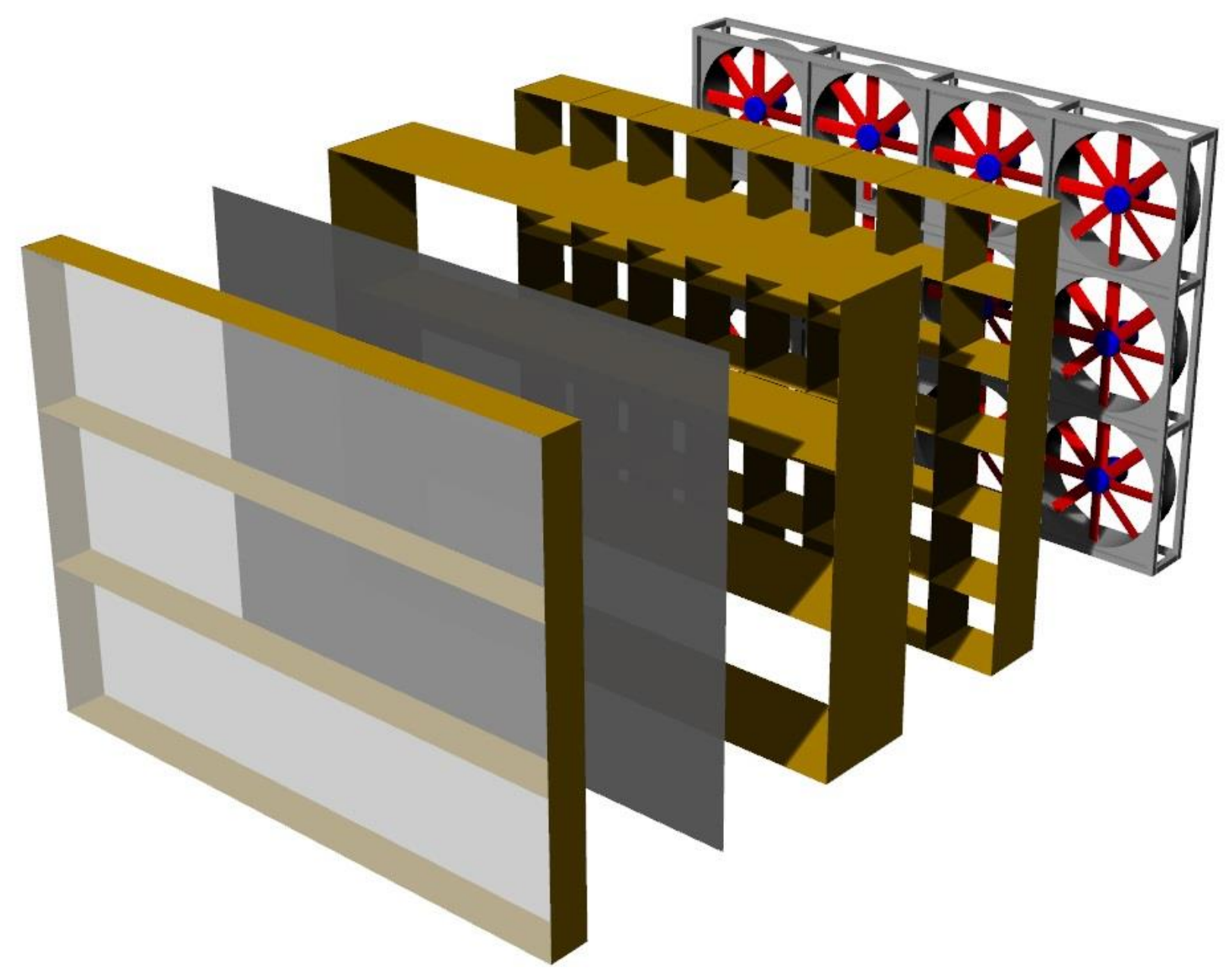

Figure 3: Flow straightener components.

\section{The wind turbine}

The present model setup is similar to the wind turbine designed by Eolink (Guyot, 2014). The reduced scale is 1:50. The range of mooring depths is equivalent in real scale to depths between $50 \mathrm{~m}$ and $300 \mathrm{~m}$. The height of the real generator is $120 \mathrm{~m}$, the rotor diameter $200 \mathrm{~m}$ and the draft of the floating platform $20.5 \mathrm{~m}$. The estimated power generation is $12 \mathrm{MW}$. Figure 4 shows an artistic view of the floating wind turbine. 


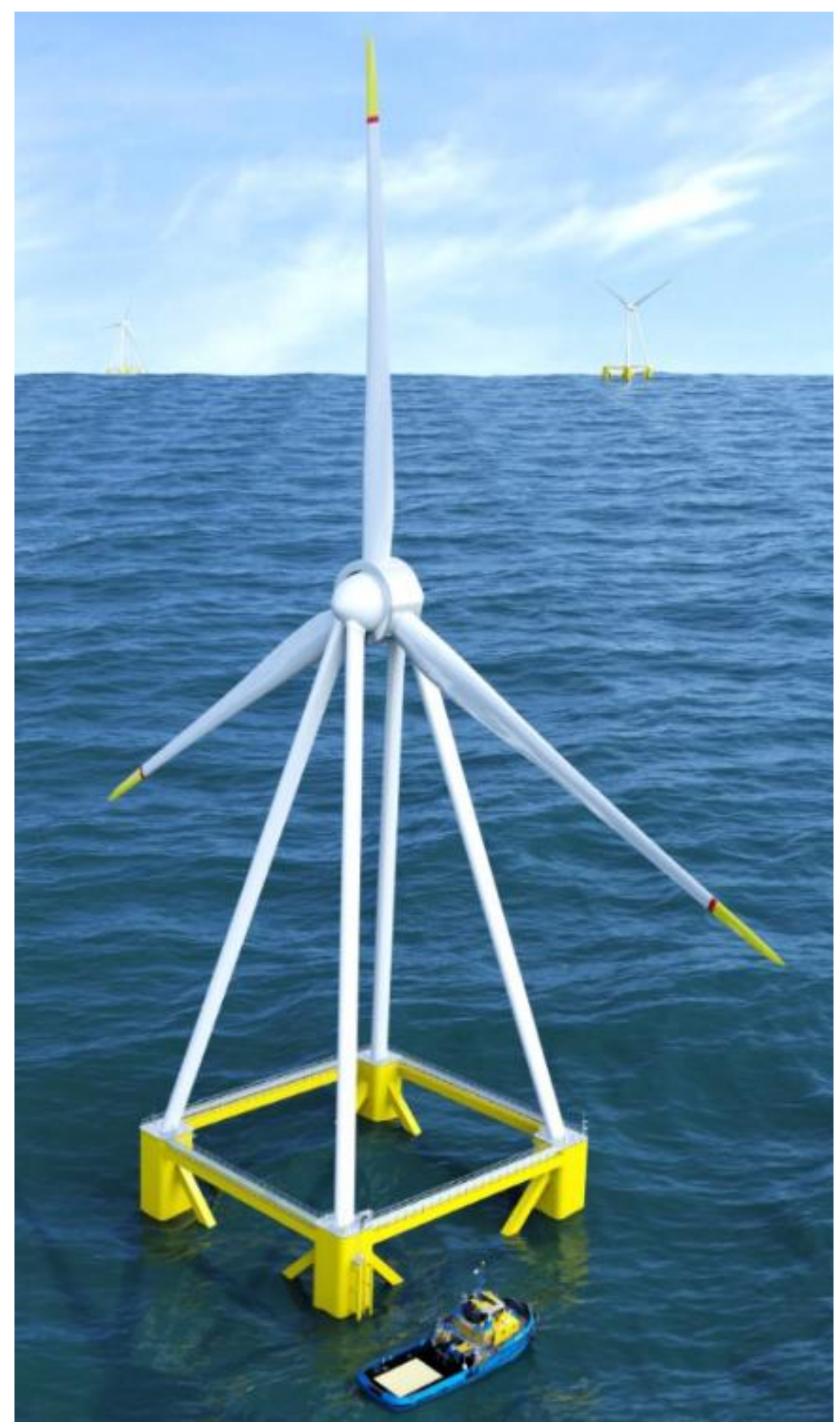

Figure 4: Floating wind turbine concept by Eolink.

The scale factor gives a rotor diameter of $4 \mathrm{~m}$. As the wind generator at Ifremer imposes a limitation of $3.2 \mathrm{~m}$, we use an extra reduction factor of 0.75 to get a diameter of $3 \mathrm{~m}$. The wind speed is increased to obtain a representative thrust according to Froude similarity. This results in an augmentation of the Reynolds number too.

The blades have a different shape than the real scale ones. Their geometry is intended to reproduce the efforts and the inertias of the real blades at Froude scale. The forces are computed with equations of the generic form $F_{x}=C_{x} \frac{1}{2} \rho S V^{2}$, where $C_{x}$ can be either $C_{l}$ or $C_{d}$. The intention is to keep the 
coefficients constant when changing the scale. This way, even if the force, the surface and the speed are affected by scale effects, we may use the coefficients directly to extrapolate the results of the experiences to the real scale.

With the preceding considerations, we have defined the geometry of the blades for our model, by determining 24 sections along the span. The first three are circular, corresponding to the root. The rest of them are NACA profiles, with variable cord and angle as a function of the distance from the axis of rotation, up to the tip. The exact shape is manufactured in composite material (Figure 5).

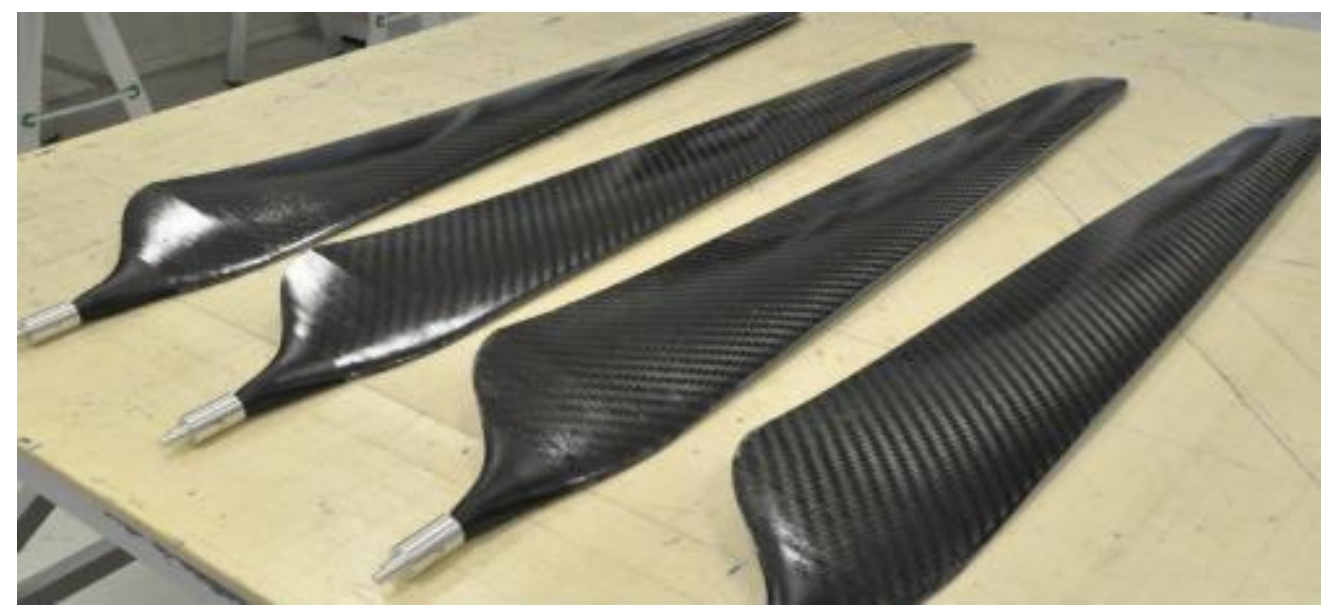

Figure 5: Blades in composite for the model.

The model counts with control devices for the pitch angle of the blades and the rotational speed (Figure 6).

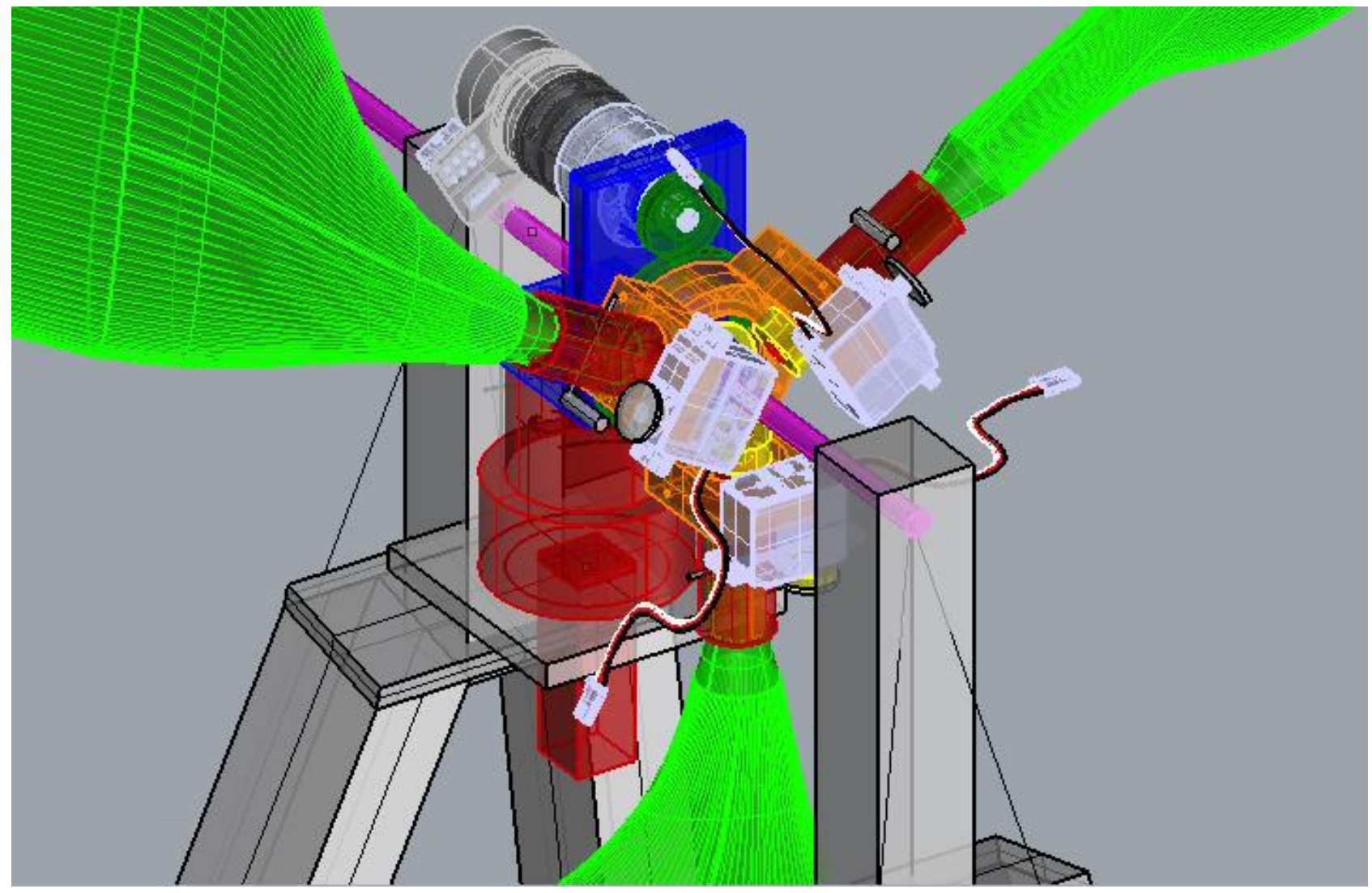

Figure 6: Mechanism for pitch and speed control in the model. 
Instead of installing the rotor at the top of a unique column, the concept of Eolink allows the distribution of the efforts in several supports. The better distribution of constraints in the structure limits both the efforts on the fixing points and the vibrations. This allows a reduction in the mass and the fabrication cost. Consequently, our model is conceived with four thin profiled arms, mounted on a rectangular floater. It is constructed in partnership with France Énergies Marines.

\section{The experiences}

The floater is attached to a buoy anchored to the bottom. This way we can verify its capacity to orientate towards the wind direction, assuring the best performance of the power generator.

The vertical position of the rotor axis ( $2.4 \mathrm{~m}$ over the water surface) must be coincident with the middle of the wind generator, so the base of this last one is elevated $0.8 \mathrm{~m}$ over the free surface (Figure 7). The rotor is placed $3 \mathrm{~m}$ downstream the wind generator, according to the research lead by Ohana (2014).

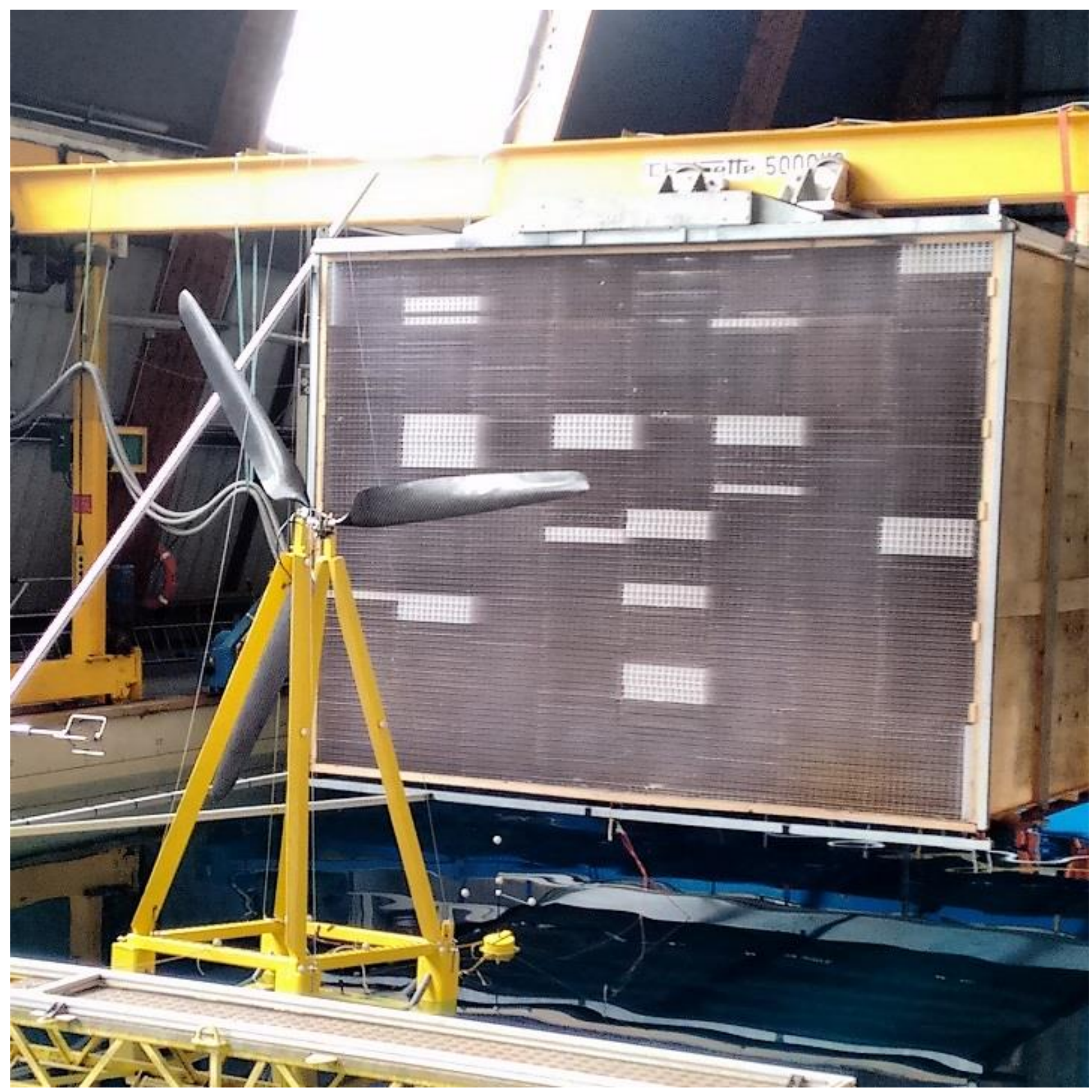

Figure 7: The model placed in front of the wind generator. 
Measuring instruments were set up around and inside the model. The floating wind turbine motions are tracked by a Qualisys camera system (Le Boulluec et al., 2013). This system enables high speed 3D motion tracking of multiple points in space. It allows us to know the movements of the floater as a rigid body in the six degrees of freedom. This data can be synchronized with measurements from other data acquisition devices.

The test matrix contains variations of these parameters: the rotor speed, the pitch of the blades, and the conditions of incident wind and waves. The measures include the three directional components of the force and the torque on the shaft, the forces on the mooring system, the rotational speed, the wind speed, and some other conditions of the tests. The acquisition frequency of all these values is $100 \mathrm{~Hz}$. In this paper we focus on the performance of the rotor, so we analyze specifically the thrust and the torque on the shaft during the steady water tests.

\section{The numerical model}

The experimental results are used to validate the numerical results. We adopt the Blade Element Momentum (BEM) method, discretizing the blades in different elements: we use the same 24 sections defined when designing the blades of the model, as shown in Figure 8.

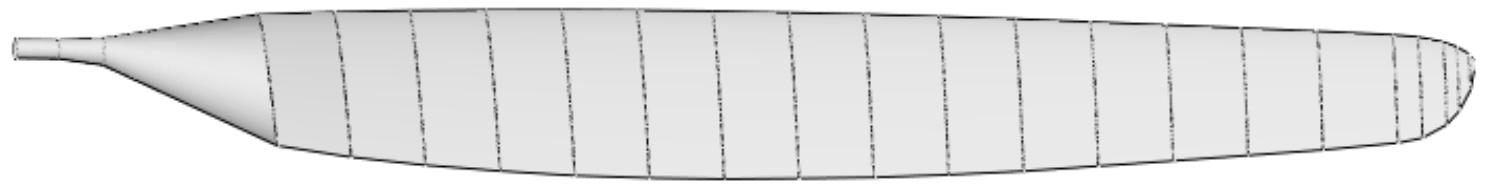

Figure 8: Sections of the blade for the simulation.

The code Xfoil (Drela, 1989) is combined to QBlade (Marten et al., 2013) to compute the loads on the rotor. Xfoil gives the lift and drag coefficients of each section of the blade. These coefficients accounts for the section geometry, the local Reynolds number and the angle of attack. Even if Xfoil has been validated many times, we have verified the accuracy of its predictions comparing them with experimental measurements.

The values given by Xfoil are limited to the cases in which the flow around the section is laminar. That is, up to an angle of incidence near $12^{\circ}$. Xfoil fails after the stall angle. It is then necessary to extrapolate the results of Xfoil to run the simulation of the rotor in QBlade. Viterna (1982) and Montgomerie (2004) have proposed two extrapolation methods to obtain the complete $360^{\circ}$ coefficients. It is found that these extrapolations give the same results in the tip speed ratio range of the experiments. The extrapolation process only affects the lowest range of the tip speed ratio (TSR <3.5). In the next section we present the results obtained with the Viterna method.

We then calculate the thrust and the torque of the rotor using the BEM method. We make these corrections to the original BEM method in QBlade: tip loss, root loss, Reynolds drag, and foil interpolation.

The performance of the rotor is represented by the power coefficient as a function of the tip speed ratio. We have simulated the behavior of the wind turbine for a series of pitch angles covering a range of $10^{\circ}$ by successive steps of $0.5^{\circ}$ (Figure 9 ). 


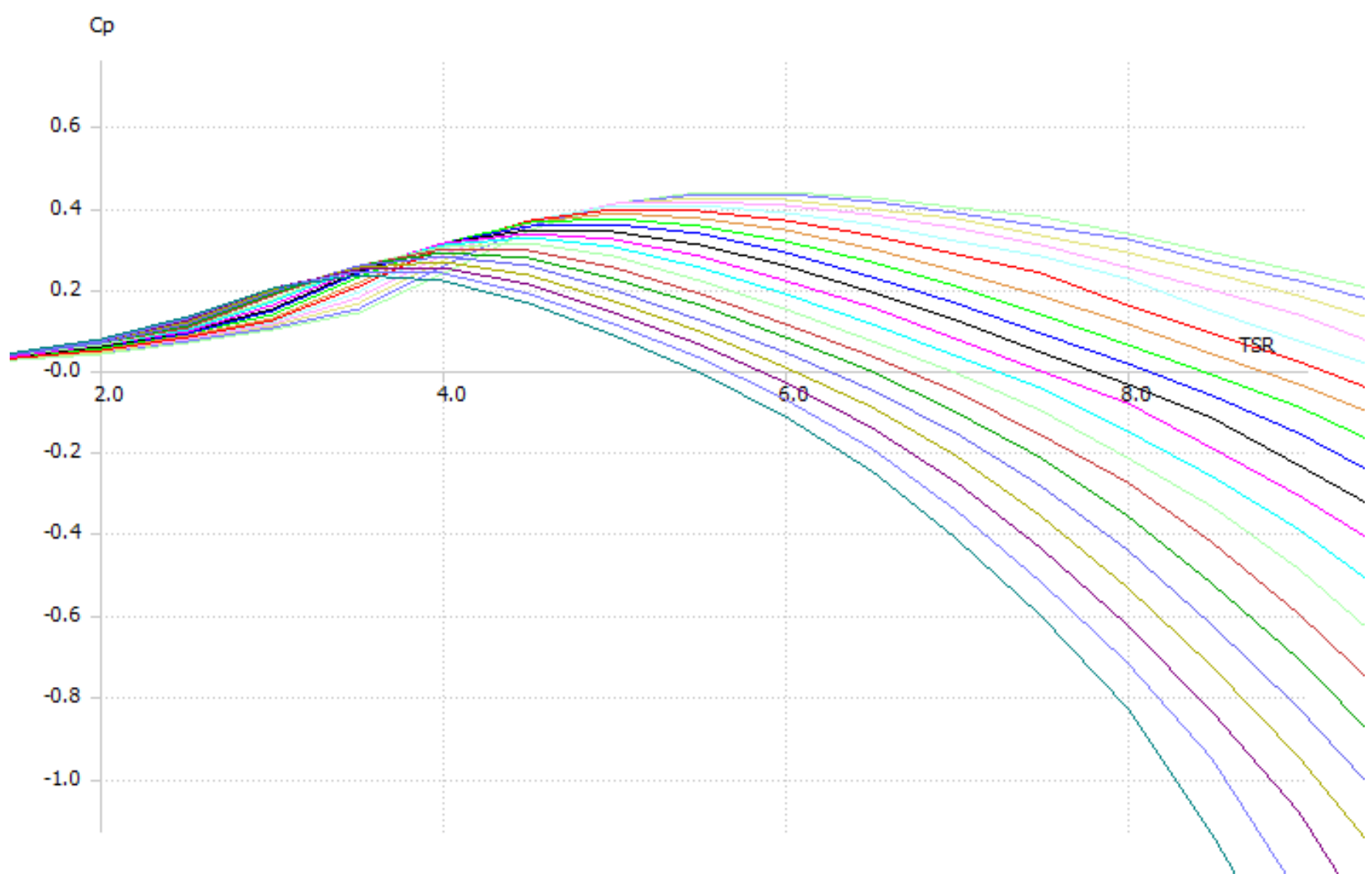

Figure 9: Performance of the rotor calculated with QBlade for different pitch angles.

\section{Results}

We analyze the following experimental data: rotor speed, wind speed, movements (translations and rotations) of the model, force and torque on the rotor shaft. We introduce this information in the next formulas to obtain the power coefficient $C p$ and the tip speed ratio TSR:

$$
\begin{gathered}
C p=\frac{Q \Omega}{\frac{1}{2} \rho S U^{3}} \\
T S R=\frac{\Omega R}{U}
\end{gathered}
$$

Figure 10 compares the power coefficient resulting from both experimental and numerical models as a function of the tip speed ratio. It includes the results corresponding to different pitch angles: $3.0^{\circ}$, $6.0^{\circ}$ and $9.0^{\circ}$. 


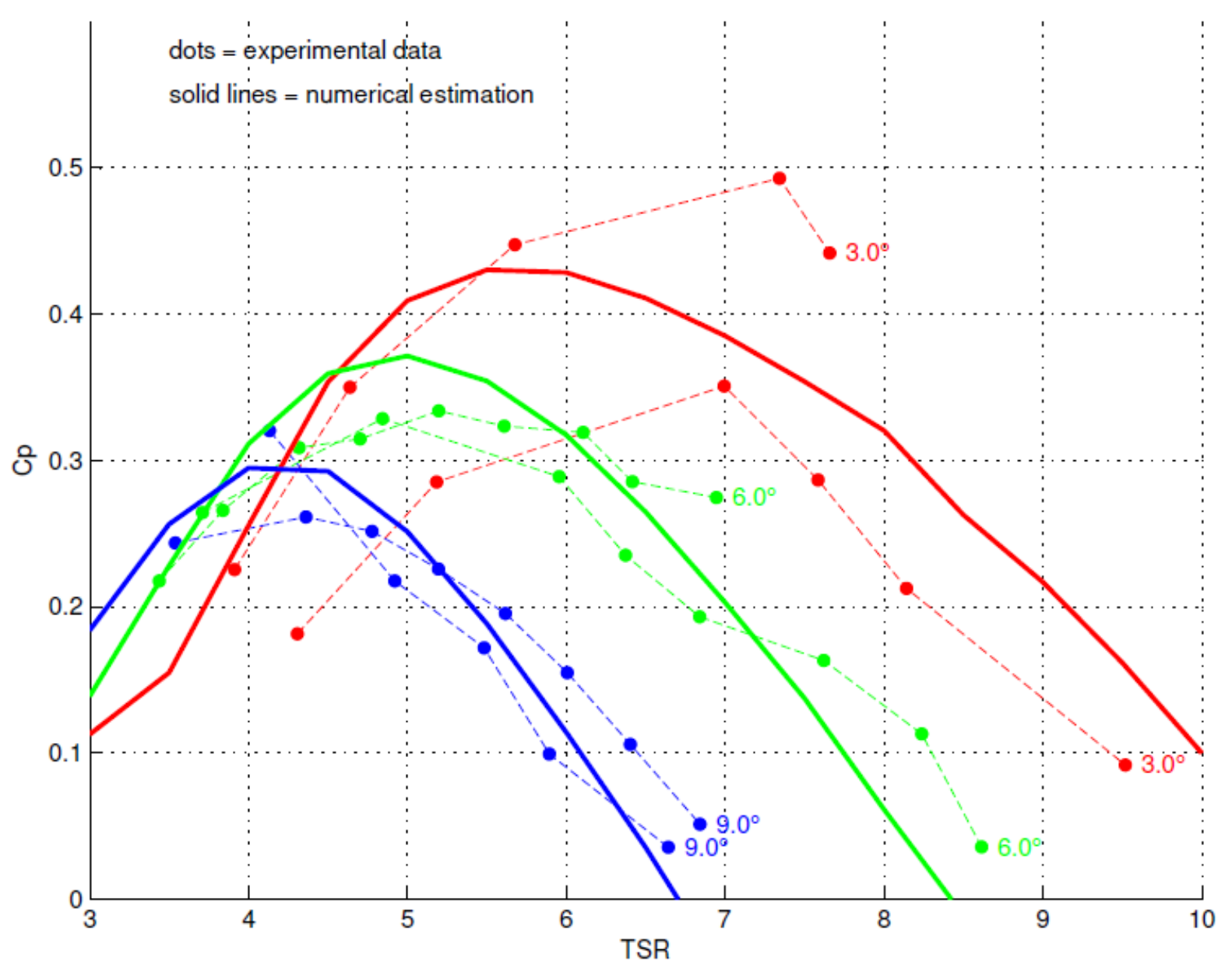

Figure 10: Comparison of the performance of the rotor with different blade pitch angles.

The dashed lines in the graph join experimental results obtained with the same mean wind speed. We can observe the agreement between the numerical results and the experimental results. For high pitch angles near $9^{\circ}$ (which correspond to smaller angles of attack of the sections of the blade) the comparison is rather good. For smaller pitch angles, there are some discrepancies between different experimental tests. It is possible that the discrepancies are partly due to the difference on wind speed measurements and its influence on the Reynolds number. The numerical results are almost between these separated experimental results.

Concerning the performance of the rotor, in the analyzed cases we obtain a maximum power coefficient of 0.49 . This means that the rotor is recovering near $83 \%$ of the maximum theoretical recoverable power given by the Betz limit. This number is comparable with the range generally reported in modern wind machines (Wang et al., 2012).

\section{Conclusions}

The experimental tests of floating wind turbines are a great asset to validate numerical simulations. Working at reduced scales requires cautious modelling skills and a good knowledge of the downscaling effects.

Our work highlights the feasibility of numerical and experimental simulation of the rotor of a floating HAWT at the early design stage. The performance of the model (represented by the power coefficient) is analyzed under different series of conditions, including rotor speed, wind speed, and pitch angle of the blades. 
We have shown that the new mast arrangement conceived by Eolink is a very fair solution considering the interaction between the fluid and the structure.

\section{Acknowledgements}

The authors thank France Énergies Marines and specially Guillaume Damblans for the general support to this work.

\section{Funding}

This work benefitted support from France Énergies Marines and the government operated by the National Research Agency in the name of Investments for the Future program and with the reference ANR-10-IED-0006-06.

\section{Declaration of conflicting interests}

The authors declare that there is no conflict of interest.

\section{References}

Drela M (1989) XFOIL: an analysis and design system for low Reynolds number airfoils. In: Low Reynolds number aerodynamics, Springer, pp. 1-12.

Guyot M (2014) Floating wind turbine structure. Patent Number: WO 2014/170027 A1.

Le Boulluec M, Ohana J, Martin A, et al. (2013) Tank testing of a new concept of floating offshore wind turbine. In: 32nd International Conference on Ocean, Offshore and Arctic Engineering, Nantes, France: American Society of Mechanical Engineers.

Marten D, Wendler J, Pechlivanoglou G, et al. (2013) QBlade: an open source tool for design and simulation of horizontal and vertical axis wind turbines. International Journal of Emerging Technology and Advanced Engineering (IJETAE) 3: 264-269.

Mehta RD and Bradshaw P (1979) Design rules for small low speed wind tunnels. The Aeronautical Journal of the Royal Aeronautical Society 83(827): 443-449.

Montgomerie B (2004) Methods for Root Effects, Tip Effects and Extending the Angle of Attack Range to $+-180^{\circ}$, with Application to Aerodynamics for Blades on Wind Turbines and Propellers. Scientific report, Stockholm: Swedish Defence Research Agency.

Ohana J, Le Boulluec M, Peron E, et al. (2014) Open jet blower type wind generator with variable wind speed capability for physical model testing of offshore structures. In: Coastlab 14, Varna, pp. 375-384.

Viterna LA and Janetzke DC (1982) Theoretical and experimental power from large horizontal-axis wind turbines. Technical report, NASA Lewis Research Center.

Wang T, Wang L, Zhong W, et al. (2012) Large-scale wind turbine blade design and aerodynamic analysis. Chinese Science Bulletin 57(5): 466-472. 